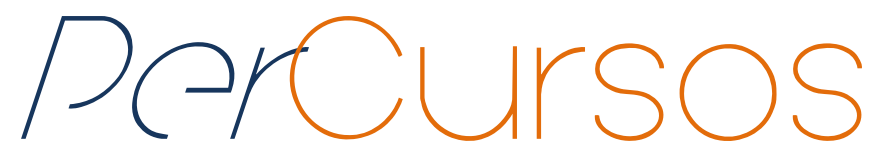

\title{
Psicologia escolar crítica e formação continuada de professores na EJA: um espaço de co-construção ${ }^{1}$
}

\begin{abstract}
Resumo
As práticas pedagógicas da escola tradicional têm excluído, ao longo da história, milhares de pessoas que não se adéquam ao seu caráter homogeneizante de aprender e se comportar. Diante disso, a educação de jovens e adultos tem um importante papel que é o de contribuir para que essas pessoas possam se apropriar dos conhecimentos historicamente produzidos, garantindo a sua humanização. Isto posto, o trabalho ora apresentado, trata-se de um relato de experiência que teve como finalidade contribuir com a formação dos professores e coordenadores da Educação de Jovens e Adultos da Secretaria Municipal de Educação de um município de Santa Catariana. O trabalho foi realizado ao longo do ano de 2014 e contou com diferentes estratégias de intervenção profissional, a saber: formação em serviço no cotidiano escolar de um núcleo de EJA; Plantões Institucionais realizados na universidade para os coordenadores de todos os núcleos e assessoria à coordenação geral de EJA do município. Visando construir um processo de formação de professores realizado "com" os professores e coordenadores e não "para" eles, partimos da vivência cotidiana dos mesmos, tendo em vista a peculiaridade da proposta pedagógica, que institui a Pesquisa como Princípio Educativo, por meio do trabalho transdisciplinar dos professores. Foi possível verificar a importância da criação de espaços formativo-reflexivos para a formação humana e técnica de professores e coordenadores, assim como para alinhar as práticas organizacionais aos princípios filosóficos que norteiam a proposta pedagógica.
\end{abstract}

Palavras-chave: Formação continuada de professores; Psicologia escolar e educacional crítica; Educação de jovens e adultos.

\author{
Adriana Bolis \\ Graduanda em Psicologia na \\ Universidade Federal de Santa \\ Catarina - UFSC. \\ Brasil \\ adribolis@gmail.com

\section{Denise Cord} \\ Doutora em Engenharia de \\ Produção pela Universidade \\ Federal de Santa Catarina - UFSC. \\ Professora da UFSC. \\ Brasil \\ cord.denise@gmail.com.br
}

\section{Leandro Castro Oltramari}

Doutor em Ciências Humanas

pela Universidade Federal de

Santa Catarina - UFSC. Professor da UFSC.

Brasil

leandrooltramari@gmail.com.br

\section{Marivete Gesser}

Doutora em Psicologia pela

Universidade Federal de Santa

Catarina - UFSC. Professora da

UFSC.

Brasil

marivete@yahoo.com.br

\footnotetext{
${ }_{1}^{1}$ Projeto Programa de Atenção e Resignificação da Queixa Escolar - PARQUE, coordenado pelo Laboratório de Psicologia Escolar e Educacional - LAPEE da Universidade Federal de Santa Catarina - UFSC.
} 


\title{
Critical educational psychology and teacher continuous training in youth and adult education: a space of co-construction
}

\begin{abstract}
Throughout the history, the pedagogical practices has been excluded a thousand of people that do not fit its homogenizing character to learn and behave. The Youth and Adults Education plays an important role contributing so that these people can take ownership of knowledge historically produced, ensuring their humanization. In this perspective, the work presented here is an experience report that aimed to contribute to the training of teachers and coordinators of Youth and Adult Education of the Municipal Department of Education in a city of Santa Catarina. The work was carried out during the year 2014 and had different professional intervention strategies: in-service training in educational daily work of a center of adult education; Institutional Shifts conducted at the university for coordinators of all adult education centers and assistance to the general coordination of Youth and Adult Education. Aiming to build a teacher training process carried out "with" them and not "for" them, we start from their daily work, considering the peculiarity of the political-pedagogical proposal, which establishes the Research as an Educational Principle, through the interdisciplinary work of teachers. It was possible to verify the importance of creating formativereflective spaces for human formation and a technical training for teachers and coordinators, as well as to align the organizational practices to the philosophical principles that guide the pedagogical proposal.
\end{abstract}

Keywords: Teacher training; Critical educational Psychology; Youth and adult education.

\section{Para citar este artigo:}

BOLIS, Adriana; CORD, Denise; OLTRAMARI, Leandro Castro; GESSER, Marivete. Psicologia escolar crítica e formação continuada de professores na EJA: um espaço de co-construção. Revista PerCursos.

Florianópolis, v. 16, n.31, p. 59 - 82, maio/ago. 2015.

\section{DOI: 10.5965/1984724616312015059}

http://dx.doi.org/10.5965/1984724616312015059 


\section{Introdução}

Diversas publicações no Brasil têm se dedicado a investigar temas relevantes para o desenvolvimento do conhecimento científico acerca da Educação de Jovens e Adultos. Nelas, são explorados temas como os índices de analfabetismo no Brasil e a exclusão da escola (SANTOS, 2003; DAVIES, 2010; FRIEDRICH, BENITE e BENITE, 2012), a evasão escolar (PEDRALLI, CERUTTI-RIZZATI, 2013), os processos de juvenilização da EJA (FURINI, DURAND e SANTOS, 2011), possibilidades de intervenção a partir do referencial da Psicologia Social (FREITAS, 2007), a formação de professores (SOARES, 2008; UNESCO, 2010; LAFFIN, 2011; LAFFIN, 2013), entre outros.

No entanto, quando nos deparamos com a complexidade da EJA, percebemos o quanto ainda são escassos os textos que discutem a atuação da Psicologia Escolar neste campo tão peculiar. Em uma dessas poucas publicações, Rodrigues, Agostinho, Gesser e Oltramari (2014) apresentam brevemente a atuação junto à EJA como espaço de formação profissional do psicólogo e destacam a relevância de esse profissional considerar o contexto histórico-cultural no qual os atores sociais da EJA estão inseridos e a necessidade de se romper com práticas patologizantes e medicalizantes das diferenças. Corroborando esta perspectiva, o presente artigo visa problematizar questões relativas à formação de professores, partindo de reflexões oriundas de uma experiência de estágio realizada na EJA de um município catarinense durante o ano letivo de 2014.

A fim de apresentarmos as peculiaridades da atuação em Psicologia na EJA, principalmente atrelada à formação de professores, iniciaremos nossas reflexões com uma breve revisão teórica acerca da Psicologia Escolar e Educacional Crítica, seguida da contextualização histórico-social da EJA no Brasil e no município em questão, destacando as idiossincrasias desta, para então problematizar os saberes e os fazeres desenvolvidos nesta experiência. 


\section{A psicologia escolar e educacional crítica}

A educação, como processo social, dá-se nas relações dos sujeitos com a cultura, com outros sujeitos, com os signos que os rodeiam e, por isto mesmo, extrapola os limites de uma instituição formal. "A educação assim compreendida no bojo da cultura (...) aborda não só aspectos relativos aos conhecimentos informais ou científicos, como também inúmeros outros ligados às construções afetivas, relacionais, criativas" (MARINHO-ARAÚJO e ALMEIDA, 2010, p. 26).

A compreensão de educação que fundamenta nossas reflexões está amplamente influenciada pela Psicologia Histórico Cultural (VIGOTSKI, 2002), segundo a qual a educação não é compreendida como “um mero ‘valor agregado’ à pessoa em formação. Ela é constitutiva da pessoa. É o processo pelo qual, através da mediação social, o indivíduo internaliza a cultura e se constitui ser humano" (PINO, 2000, p. 57, grifos do autor). Desta forma, entende-se que a educação não está restrita ao espaço da escola ou aos conhecimentos formais, chamados "científicos", mas acontece nas mediações das quais o sujeito participa.

Entretanto, no atual contexto histórico-cultural brasileiro, "a escola tem um lugar privilegiado como lócus dos principais processos educativos intencionais" (MARTINEZ, 2010, p. 41). Neste sentido, Martínez conceitua a Psicologia Escolar como

um campo de atuação do psicólogo (e eventualmente de produção científica) caracterizado pela utilização da Psicologia no contexto escolar, com o objetivo de contribuir para otimizar o processo educativo, entendido este como complexo processo de transmissão cultural e de espaço de desenvolvimento da subjetividade. (MARTINEZ, 2003, citada por MARTINEZ, 2010, p. 41)

Cabe lembrar que a Psicologia tem um longo percurso histórico ao lado da Educação (principalmente escolar) no Brasil, e vem se construindo, repensando bases epistemológicas, atualizando saberes e práticas, acompanhando as mudanças sociais e históricas, em constante transformação nesse campo de atuação. Inicialmente focada em 
“problemas" individuais/individualizantes de aprendizagem e de comportamento, a atuação da Psicologia Escolar vem sendo ampliada, promovendo uma compreensão mais contextualizada dos fenômenos (MARINHO-ARAÚJO e ALMEIDA, 2010; SOARES e MARINHO-ARAÚJO, 2010; MARTINEZ, 2010; CARVALHO, 2003).

Neste sentido, Martínez (2010) aponta que, sem abandonar totalmente alguns métodos ditos "tradicionais" de atuação, os psicólogos escolares vêm adotando práticas emergentes, que visam a intervenções mais amplas no contexto escolar. Por exemplo: mantêm-se as práticas como a orientação de pais e professores, a atuação na formação de professores, a coordenação de projetos educativos e a avaliação psicológica; entretanto, somam-se a estas práticas a análise institucional, a participação na elaboração dos projetos político-pedagógicos, as contribuições para a coesão da equipe pedagógica, entre outras.

Estas transformações na práxis da Psicologia Escolar ocorrem principalmente em função da ampliação na compreensão dos fenômenos. Assim, ao adotarmos o referencial vigotskiano, cabe compreender os fenômenos em sua localização histórica e cultural e, desta forma, considerar a complexidade dos mesmos em nossas intervenções. Neste modelo, ficam obsoletas as práticas que consideram os problemas de forma polarizada, restritiva e individualizante, sem compreender o sujeito, sua relação com o contexto e sua história.

Para tanto, a proximidade dos contextos cotidianamente vivenciados pelos atores/sujeitos da/na escola torna-se indispensável à prática da Psicologia Escolar Crítica. Faz-se necessário um esforço por parte dos psicólogos em "habitar o processo de produção das maneiras de agir e de pensar, das formas de subjetivação presentes no processo de escolarização" (MACHADO, 2011, p. 62). Dessa maneira, de acordo com Gesser (2013), é possível romper com modelos normalizantes e patologizantes, além de construir práticas educativas voltadas à valorização das diferenças e garantia dos direitos humanos. 


\section{A EJA no Brasil e no município em questão}

A fim de contextualizar este campo de atuação, cabe apresentar um breve histórico da Educação de Jovens e Adultos no Brasil e no município estudado.

Apesar de a LDB (Lei de Diretrizes e Bases) de 1996 já conter a EJA como modalidade de educação básica nos níveis fundamental e médio, temos como um dos marcos importantes na constituição da modalidade específica de Educação de Jovens e Adultos, a V Confitea (Conferência Internacional sobre Educação de Adultos), que aconteceu em Hamburgo - Alemanha, em 1997, e promoveu um impulso significativo para a sistematização da EJA no Brasil (BERGER, 2009; BRASIL, 1996).

Referenciadas em Paulo Freire, as primeiras iniciativas dessa modalidade atendiam a um público adulto, geralmente pertencente a camadas urbanas populares que conservavam hábitos rurais, e que não tiveram acesso à escolarização. Porém, segundo Berger (2009), a história da EJA mostra que esta vem se "juvenilizando", ou seja, cada vez mais jovens se matriculam nessa modalidade de ensino, o que pode ser entendido como denúncia das falhas processuais e da produção de fracasso escolar do sistema seriado de educação atual. A exclusão, que antes se dava por falta de vagas, agora se dá pela defasagem no aprendizado.

É interessante destacar que, desde os primeiros documentos que regulamentam a EJA, é levada em consideração a necessidade de adequação do modo como esta modalidade será oferecida às particularidades dos sujeitos. Assim sendo, a EJA,

considerada apenas como uma forma diferente deste nível da educação, tem especificidades em relação aos sujeitos, aos quais a modalidade se destina. É em função disto que não existem diretrizes curriculares para a EJA, mas sim para o Ensino Médio e para o Ensino Fundamental. A lei prevê, portanto, a necessidade de adequação da oferta às necessidades dos educandos, abrindo possibilidades, inclusive, para aferimento de conhecimentos obtidos fora da escola. (BERGER, 2009, p. 31)

Podemos perceber, desde já, que tal consideração está baseada numa compreensão ampla de educação que, como citado por Berger (2009), procura integrar o 
conhecimento construído na escola ao conhecimento obtido fora dela. Destaca-se que essa visão é coerente com os referenciais da Psicologia Escolar Crítica, mencionados anteriormente (MARTINEZ, 2010; MADUREIRA, 2013).

Outro marco importante foi a realização da VI Confitea no Rio de Janeiro, em 2009, na qual foram propostas e revisadas políticas públicas para essa modalidade de educação. Em preparação para a conferência mundial, nos fóruns regionais e estaduais e, particularmente, no município estudado (em função do processo de construção do Plano Municipal de Educação), foram efetivados diversos debates, os quais suscitaram propostas e avaliações das ações na Educação de Jovens e Adultos. A partir desses debates, foi construída a proposta que fundamenta a estrutura, o funcionamento e a prática na Educação de Jovens e Adultos do município (FLORIANÓPOLIS, 2009).

Segundo o documento que sistematiza a proposta acima referida, constatou-se que os "alunos buscam a EJA por três motivos principais: a certificação, aprender mais e conseguir um emprego melhor" (FLORIANÓPOLIS, 2009, p. 7). Neste sentido, a proposta pretende garantir educação em um sentido amplo, através de "um currículo onde conteúdos procedimentais e atitudinais são tão ou mais importantes que os conceituais" (FLORANÓPOLIS, 2009, p. 7). Com base nesta perspectiva de currículo, a EJA, nesse município, consolidou sua proposta curricular institucionalizando a Pesquisa como Princípio Educativo.

Em consonância com o indicativo de adequar a modalidade à realidade dos sujeitos da EJA, a Pesquisa como Princípio Educativo prevê que o acesso ao conhecimento se dê através de pesquisas realizadas pelos estudantes, com temas do seu interesse, partindo do seu conhecimento prévio. Os professores das diversas disciplinas português, matemática, história, artes, educação física, etc. - trabalham juntos em sala de aula, visando a uma atuação profissional transdisciplinar.

Segundo Almeida Filho (1997, p. 10), a transdisciplinaridade tem sua coordenação “assegurada por referência a uma finalidade comum, com tendência à horizontalização das relações de poder. Implica a criação de um campo novo que idealmente desenvolverá uma autonomia teórica e metodológica perante as disciplinas que o compõem”. Tonetto 
e Gomes (2007, p. 89) afirmam que o trabalho "é transdisciplinar quando as ações são definidas e planejadas em conjunto". Na experiência ora relatada, observou-se que o planejamento das aulas foi realizado semanalmente pela equipe de professores, juntamente com o coordenador, e o objetivo comum do grupo era a apropriação do conhecimento pelos estudantes. No entanto, como discutiremos ao longo do texto, a meta da transdisciplinaridade se mostra deveras desafiadora.

A própria forma como a EJA é estruturada no município é coerente com a proposta idealizada. A estruturação em núcleos que operem nos bairros visa facilitar o acesso aos estudantes. Assim, é composta por onze núcleos distribuídos por bairros da cidade, de maneira a estar localizada próxima da população. Cada núcleo é composto por um coordenador e em média dez professores de diversas disciplinas e ao menos um professor alfabetizador. Alguns núcleos possuem ainda uma segunda unidade de funcionamento, que visa facilitar ainda mais o acesso aos estudantes por localizar-se em lugares remotos dos bairros, sendo conhecidas como "polos" e geralmente operando em centros comunitários, salas cedidas por organizações sindicais ou religiosas, havendo um polo que funciona num barracão de coleta de material reciclado, por exemplo.

Do ponto de vista da organização do trabalho, a gestão é distribuída entre os coordenadores dos núcleos. Ao coordenador cabe gerir o grupo de professores, coordenar as ações interdisciplinares e facilitar a formação continuada em serviço, organizando e conduzindo as reuniões de planejamento, mediando os conflitos. Além de ser o gestor do núcleo, ou seja, de ser o responsável por prestar contas dos gastos, do número de matrículas e formaturas, acompanhar os alunos em suas trajetórias, divulgar a EJA no bairro, entre outras atribuições que podem ser delegadas aos professores por estarem sob o mesmo princípio do trabalho compartilhado.

Para gerir todos os núcleos, há a equipe da coordenação geral da EJA no município que, além das atribuições administrativas e burocráticas, promove ainda encontros mensais de formação continuada com os professores e coordenadores de todos os núcleos, encontros regionais em que se reúnem as equipes de três a quatro núcleos, e a formação de coordenadores, na qual a Psicologia tem tido importantes contribuições, através dos Plantões Institucionais. 


\section{EJA: um campo fértil em potências e desafios}

Nesta seção, pretendemos aproximar o leitor da realidade vivenciada pelos atores da EJA no município estudado e, para tanto, vamos apresentar, na forma de potências e desafios, algumas das reflexões suscitadas no decorrer de uma experiência de estágio em Psicologia Escolar, cujo foco foi a formação de educadores na EJA.

Frente a histórias de vida escolar marcadas pela exclusão, pela negligência e pela invisibilidade, a EJA se dispõe justamente ao contrário: oferecer aos alunos um espaço que integre o processo de apropriação do conhecimento historicamente construído com a socialização, a expressão, a reflexão, e com a apropriação dos espaços da cidade, como forma de acesso ao conhecimento e à cultura. "O trabalho com os interesses, necessidades e problemas dos alunos não são as finalidades inerentes nesta Educação e sim o MEIO pelo qual se produzem as relações e os movimentos para um entendimento e intervenção intencional na realidade" (NUNES, in: SMEF, 2009, p. 29, grifo do autor). E é justamente aí que reside sua maior potência.

As pesquisas desenvolvidas pelos educandos variam desde a busca por compreender temas atuais, como o aquecimento global, drogas, DSTs e outras doenças crônicas, até a vida e obra de artistas e músicos, o funcionamento de motores de carros, o surgimento do skate, entre outras tantas temáticas. A escolha do assunto geralmente resulta de algum afeto dos estudantes, seja por integrar sua experiência de vida ou por despertar seu interesse estético-político ou intelectual. Em paralelo às pesquisas, as oficinas, os projetos e as saídas pedagógicas têm um papel fundamental nos processos educativos, na apropriação, por parte destes sujeitos, da cultura da qual são produtos e produtores. Entre as oficinas e os projetos realizados durante o período do estágio no Núcleo que acompanhamos, destacam-se: Música no intervalo, Movimente-se, Horta Vertical, Reciclagem, Oficina das calorias, Aquecimento Global, Grupo de teatro, Astronomia, Projeto de Letramento, Troca de papéis. Mediar um processo educacional com estas características exige dos professores uma disponibilidade vincular e referencial que ultrapassa a perspectiva cognitivo-metodológica, requerendo o constante desenvolvimento de novas habilidades relacionais e de estratégias pedagógicas. 
Outra potência presente no campo é a proposta de trabalho conjunto em que a equipe pedagógica é, conforme especificado anteriormente, composta por um grupo de professores e por um coordenador. Os planejamentos em grupo permitem a discussão de casos, a troca de ideias, o compartilhamento de experiências e a elaboração conjunta de estratégias educativas. O mesmo ocorre quanto à co-docência, visto que os professores vão para a sala de aula em duplas ou trios e compartilham o atendimento aos alunos, auxiliando-os nas pesquisas com o conhecimento específico oriundo de sua formação inicial e geral, borrando as barreiras entre as disciplinas e focando a relação com o conhecimento e não com os conteúdos em si.

Entretanto, em meio ao desenvolvimento das atividades, o cotidiano escolar é atravessado por diversas questões desafiadoras, e o que por um lado se apresenta como uma potência, por outro implica trabalho árduo e processual, característico das mudanças de paradigma. Assim, dentre as diversas demandas e problemáticas observadas, destacamos algumas:

- $\quad$ as dificuldades de transmissão e apropriação dos princípios que embasam a abordagem pedagógica dos conteúdos a partir da pesquisa;

- os desafios de trabalhar em equipe, abandonando o modelo "tradicional" de ensino e operando a partir de um método diferente, para além das fronteiras disciplinares tão evidenciadas nos processos formativos dos professores;

- os desafios na relação com os alunos frente a fenômenos manifestos no cotidiano da prática pedagógica, tais como apatia, desmotivação, uso de drogas, baixo letramento, faltas, descontinuidade, perda do interesse pelo tema da pesquisa, dificuldades para trabalhar em grupo, conflitos intergeracionais, conflitos próprios da adolescência, uso de celular nas aulas, dificuldade de falar em público, evasão, condições sociais limitantes, entre outros;

- $\quad$ o desafio experienciado pelos coordenadores dos núcleos, de exercer a função junto a um grupo de professores segundo os princípios da EJA, sendo eles também professores, somado ao desafio de liderar grupos de professores diferentes a 
cada ano, devido às características do contrato de trabalho temporário da maioria dos profissionais atuantes nessa modalidade educacional neste município;

- os desafios comuns à categoria profissional de professores (nesse município ocorre greve anualmente no mês de maio, mês de negociação salarial);

- além disso, a modalidade de contratos temporários de trabalho de cerca de 90\% do corpo docente da EJA produz ansiedade e estresse, devido à insegurança e descontinuidade no trabalho, e dificuldade na compreensão da proposta pedagógica.

É importante salientar que, ao descrever os desafios acima, focou-se intencionalmente nas problemáticas vivenciadas pelo corpo docente e pela coordenação pedagógica do núcleo, sem incluir o universo estudantil, como forma de delimitar o campo de intervenção que caracterizou esta experiência de estágio. Frente a esse cenário complexo, muitas vezes nebuloso e bastante paradoxal, foi necessário eleger as questões que nos pareciam emergentes e possíveis de abordar - dentro de nossas limitações de tempo, espaço, experiência e alcance teórico-prático -, tais como a comunicação nos e entre os diversos níveis da EJA, a apropriação e prática da proposta político-pedagógica por seus atores (estudantes, professores e coordenadores) e o processo de formação continuada, cuja análise será aprofundada neste trabalho.

\section{Intervenções da psicologia na formação continuada de professores da EJA}

Dado um panorama geral do nosso campo de atuação, vamos agora compreender onde se iniciam nossos laços. Com a proposta de aproximar os conhecimentos produzidos pela academia acerca da Psicologia Escolar e Educacional no contexto da UFSC (Universidade Federal de Santa Catarina), através do LAPEE (Laboratório de Psicologia Escolar e Educacional), da realidade da educação pública, foi criado o projeto PARQUE - Programa de Atenção e Ressignificação das Queixas Escolares. Através deste projeto, foi firmada uma parceria entre a Universidade e a Secretaria Municipal de Educação de um município catarinense. Parceria na qual um dos elos é a realização de estágios curriculares de estudantes do curso de graduação em Psicologia junto à EJA. 
O projeto PARQUE adota a perspectiva da Psicologia Escolar e Educacional Crítica, que problematiza a atuação da Psicologia, ampliando as possibilidades de compreensão dos fenômenos relativos aos processos educacionais e consequentemente as possibilidades de intervenção dos psicólogos. Em consonância com esta perspectiva, os diálogos entre a Psicologia e a EJA vêm se constituindo em uma relação dinâmica e dialógica, em que a atuação dos estagiários de Psicologia está sempre em transformação, acompanhando e criando novas demandas no campo de estágio. Da mesma forma que a EJA se transforma no processo de (re)pensar suas práticas, alteram-se as nossas propostas, as formas e os locais de intervenção.

No caso da experiência que inspirou este texto, nossa atuação deu-se nos seguintes níveis da EJA:

- coordenação geral da EJA no município: acompanhamento das ações da coordenação, através de entrevistas e reuniões com o coordenador geral; acompanhamento e planejamento dos Plantões Institucionais de coordenadores dos núcleos, coordenados por professores da Universidade; acompanhamento dos processos de formação continuada de professores;

- $\quad$ equipe pedagógica de um dos núcleos: acompanhamento e intervenção nas atividades realizadas no núcleo: aulas, planejamento conjunto e reuniões da equipe pedagógica, com foco no grupo composto por nove professores e um coordenador e na formação em serviço.

Procurou-se, durante o período de estágio, desenvolver uma compreensão ampla dos fenômenos e formas efetivas de intervenção, a fim de promover a articulação das ações entre esses níveis, levando em consideração os sujeitos que compõem a EJA e as particularidades de cada contexto. Durante o período de observação, buscou-se depreender as relações entre os diversos atores, bem como a dinâmica de funcionamento do contexto educacional, de modo a reconhecer como se dá o processo de ensinoaprendizagem por meio da mediação entre alunos e professores; as relações de trabalho; o processo de formação continuada e o planejamento e execução das ações da 
coordenação geral, buscando com isto ter uma compreensão maior da complexidade do fenômeno para efetivar a intervenção junto à formação destes professores.

Cabe ressaltar que o estágio foi realizado em dupla, sendo que no primeiro semestre a autora principal deste trabalho compartilhou a experiência com um colega que também atuara no semestre anterior, e no segundo semestre, acolheu a nova estagiária. Essa forma de circulação de estagiários no contexto, na qual aquele que chega é acolhido pelo mais experiente, objetiva minimizar os efeitos da descontinuidade nas intervenções e vínculos estabelecidos com a instituição e seus atores. Com isso, estabeleceu-se um continuum, o qual possibilitou que tanto as práticas dos estagiários quanto as do campo fossem menos afetadas pelas mudanças de mediação de um semestre para o outro.

\section{Intervenção junto a um núcleo de EJA}

O objetivo da atuação na instância de um Núcleo da EJA foi o de promover a formação de professores no grupo, visando a uma vivência mais fluida do papel de educador, tendo em vista as particularidades próprias da proposta de ensino e aprendizagem na EJA. Após uma leitura cuidadosa do contexto e daquele grupo específico, suas possibilidades e seus limites, percebemos a necessidade de iniciar a intervenção no grupo pela promoção de um encontro entre esses sujeitos, para que se conhecessem melhor e pudessem de fato trabalhar juntos, como um grupo, e não apenas como uma equipe de trabalho que convive em meio às tarefas do cotidiano. Percebemos que essa potência não vinha sendo explorada, não por indisposição, mas pelo atropelamento dos desafios diários, pela burocratização do processo de trabalho e pela sobreimplicação. Sobre esta última, trata-se de

uma dificuldade de análise e que, mesmo quando realizada, pode considerar como referência apenas um único nível, um só objeto, impossibilitando que outras dimensões sejam pensadas, que as multiplicidades se façam presentes, que as diferentes instituições sejam consideradas. (COIMBRA e NASCIMENTO, 2007, p. 30) 
Neste sentido, o conceito de sobreimplicação tem relação com dispositivos que influenciam diretamente a atividade laboral dos educadores, pois surge devido ao acúmulo de atividades e urgências que fazem com que os mesmos naturalizem intervenções cada vez mais rápidas, sem a possibilidade de uma reflexão necessária sobre a atividade e o seu objetivo. Assim, em muitos casos, situações de menor importância, mas maior urgência, acabam sendo colocadas à frente de atividades fins e de maior relevância ao trabalho docente.

Foram realizados quatro encontros sistematizados, em local distinto da sala de reuniões. É importante ressaltar que, durante todos os momentos em que estivemos com o grupo ao longo do ano letivo, diversas intervenções foram realizadas. A participação dos estagiários como integrantes do grupo, mas desempenhando papéis diferentes - de psicólogos escolares e educacionais -, é considerada uma forma de intervenção na perspectiva crítica de atuação do psicólogo nas escolas (MARINHO-ARAÚJO, 2010; MARTINEZ, 2010; MACHADO, 2011).

Tecnicamente, as intervenções no grupo estiveram também apoiadas em conceitos da teoria psicodramática de Jacob Levy Moreno. Não sendo o foco deste texto, apenas apresentamos alguns conceitos fundamentais para contextualizar nossas intervenções. Entretanto, para uma compreensão mais apurada de tais conceitos, indicamos ao leitor a consulta aos referenciais indicados - Nery (2008; 2010), Moreno (1959/1983) e Faleiros (2004).

Apresentamos aqui especialmente o conceito de papel, o qual, de acordo com Nery (2010), é a base para sua teoria de grupos:

Os papéis sociais existentes numa sociedade e cultura são preexistentes ao "eu", como formas de funcionamento do indivíduo em uma situação. Os papéis sociais estruturam e operacionalizam o "eu", fornecendo-lhe plasticidade e estética em adequação ao papel complementar do outro, ao contexto e ao momento. (NERY, 2010, p. 20) 
Outro aspecto fundamental dessa teoria, e que influenciou nosso trabalho, é a questão da coexistência, do ser em relação:

Do ponto de vista de Moreno, o homem é sempre considerado em relação com o seu próximo: existir é coexistir, é existir com o outro, mas também é considerado na perspectiva do tempo vivido, intimamente vinculado à inter-relação e à criação. (FALEIROS, 2004, p. 20, grifos da autora)

Nesta perspectiva, objetivou-se, com as intervenções no grupo, facilitar processos de ressignificação de aspectos obstaculizados da vivência do papel de professor, os quais causavam sofrimentos expressos no conjunto dos professores como insegurança em relação à efetividade de suas práticas educativas. Para tanto, as intervenções acompanharam o seguinte planejamento: no primeiro encontro trabalhamos, a partir da aplicação de uma técnica psicodramática, a vinculação com o papel de professor e o resgate do sentido deste papel social para cada um. No segundo encontro, retomamos a questão do vínculo, promovendo a reflexão sobre as particularidades de ser professor de EJA, considerando-se a proposta vigente no município e a nova forma de ser/fazer a docência compartilhada em uma perspectiva interdisciplinar. Nessa ocasião, deixamos emergir as temáticas do grupo, definindo como tema para o próximo encontro o “comprometimento com o trabalho". No terceiro encontro, retomamos a temática propondo que a redução fenomenológica fosse feita pelo grupo, através de um instrumento pedagógico: o mapa de pesquisa. Dessa forma, o grupo deveria abrir a temática central em temáticas menores, que constituíssem ou influenciassem a primeira. O último encontro foi dedicado ao fechamento do trabalho.

Consideramos que tais intervenções marcaram um momento importante nesta parceria entre EJA e LAPEE. O vínculo com o coordenador e os professores do núcleo possibilitou vivenciar e observar a dinâmica de trabalho cotidiana. As intervenções realizadas permitiram a emergência de questões pedagógicas e institucionais, que ficavam no "plano de fundo", mas influenciavam a forma de trabalho de todos (como as 
dúvidas e críticas à forma de aplicação da proposta pedagógica, a situação empregatícia precária da maioria dos professores e a insegurança que ela gera, entre outras) para que pudéssemos compreendê-las e assim lidar com elas.

O planejamento acordado com a equipe teve de ser reduzido para adaptar-se ao tempo que a equipe disponibilizou para as intervenções. Apesar disso, avaliamos positivamente o fato de que as mobilizações e problematizações realizadas afetaram sutilmente a dinâmica do grupo de professores. Isso pôde ser observado tanto nas reuniões de planejamento quanto em sala de aula, pela forma como os problemas passaram a ser acolhidos e problematizados, ainda de uma forma rudimentar, mas já não sendo silenciados, pois havia algum suporte para poder olhar essas questões. Importante recordarmos ainda que esses afetos continuarão instrumentalizando o trabalho daqueles profissionais, onde quer que venham a exercer seus papéis como educadores.

O trabalho realizado no Núcleo junto aos seus profissionais pode ser caracterizado como formação em serviço. Essa atividade contribuiu tanto para que os professores e o coordenador desse núcleo pudessem planejar o trabalho de forma mais integrada e próxima à transdisciplinaridade, como também para subsidiar uma outra estratégia de intervenção profissional realizada, que consistiu no Plantão Institucional.

\section{Intervenções junto à coordenação geral e aos coordenadores dos núcleos da EJA}

Neste tópico, abordaremos as intervenções junto à coordenação geral da EJA e as realizadas junto aos coordenadores dos núcleos e os seus efeitos para a implementação de alguns princípios da EJA.

A decisão por intervir junto ao coordenador geral da EJA no município se deu após a constatação de que muitas das demandas de intervenção, elencadas como importantes e/ou urgentes, não eram características somente do núcleo que acompanhávamos, mas da EJA como um todo. Dessa forma, entendeu-se que, atuando junto à coordenação geral, a amplitude da intervenção seria maior, assim como a sua efetividade. Delineamos como objetivos: a) sensibilizar a coordenação sobre a necessidade de formação dos 
professores para a proposta político-pedagógica da EJA; b) auxiliar na construção de um processo de formação contínuo e voltado aos aspectos teóricos e metodológicos da proposta; c) garantir um espaço de discussão das práticas, que possibilitasse a expressão das críticas de educadores e educandos, visando à melhoria dos processos educativos e de trabalho.

A primeira estratégia utilizada foi a realização de entrevistas reflexivas junto à coordenação geral da EJA. O referencial da entrevista reflexiva é considerado "como uma situação de trocas intersubjetivas":

se, na sua essência, uma entrevista é uma situação de interação humana, estamos respondendo aos estados emocionais e índices não-verbais que nosso interlocutor está emitindo, o que não significa "adivinhar" o que o outro está sentindo - o que é impossível - mas descrever a impressão que nos causou. (SZYMANSKI, 2010, p. 40)

A eleição do referencial teórico deu-se pela intenção de proporcionar reflexão e elaboração por parte do coordenador, a fim de conhecer a visibilidade e importância atribuída às questões depreendidas durante as observações no núcleo, decorrentes da escuta dos estagiários aos professores(as) e alunos(as). Como a proposta do estágio foi a de atuar em rede, buscou-se dialogar sobre os limites e as possibilidades da nossa atuação frente às demandas levantadas. Buscou-se, além de indicar os "problemas", construir uma compreensão conjunta e encontrar soluções possíveis, de forma a verificar a pertinência dos apontamentos e as condições que o campo tem de absorver/lidar com estas demandas, promovendo a implicação dos atores da EJA durante todo o processo e, ao mesmo tempo, evitar a sobreimplicação dos mesmos através das reflexões propostas pelo método.

Nas entrevistas, apontamos que, dentre as questões que nos pareceram mais emergentes, destacavam-se as dificuldades na comunicação, a descontinuidade do processo de formação, o abafamento das críticas e a consequente fragilidade na compreensão da proposta pedagógica. Essas questões atravessavam o trabalho e a 
convivência entre os profissionais, gerando conflitos e ruídos na comunicação; situações ansiogênicas devido às dúvidas a respeito de um fazer pedagógico que estivesse em consonância com a proposta; a angústia e o estresse acumulados devido à falta de oportunidade de compartilhamento, de expressão e (re)significação dos papéis de professor(a) e de coordenador(a). Procedeu-se a uma síntese a partir da qual se procurou buscar possibilidades de mediação nos espaços de formação já existentes para acolher esta demanda, bem como a criação de novos espaços.

Com base nos resultados da entrevista com o coordenador geral da EJA, identificou-se a necessidade de propiciar um espaço no qual os coordenadores dos onze núcleos de EJA do município tivessem a oportunidade de construir estratégias para lidar com as problemáticas vivenciadas cotidianamente por eles. Levando em conta tal necessidade, outra estratégia utilizada foi a realização de Plantões Institucionais, que abrangeram encontros mensais com os coordenadores de núcleo no Serviço de Psicologia da Universidade e eram mediados pelos professores supervisores acadêmicos do estágio. O "Plantão Institucional” é uma modalidade de intervenção em Psicologia Escolar caracterizada pela disponibilidade da equipe em acolher demandas que, por vezes, são formuladas a partir de uma situação emergencial (LERNER, FONSECA, SAYÃO e MACHADO, 2014). Essa estratégia potencializa a troca de experiências e propicia a reflexão e a criação de estratégias voltadas à compreensão e intervenção nas situações do cotidiano, considerando a complexidade dos elementos que as constituem.

O espaço dos Plantões Institucionais mostrou-se muito rico, por se constituir como um local de discussão, reflexão e alinhamento de práticas entre os coordenadores, cujos "efeitos" eram percebidos nos demais contextos da EJA, tal como as salas de aula dos núcleos. A participação nesse contexto possibilitou depreender que as problematizações explicitadas nos núcleos pelos professores estavam em questão também para os coordenadores de outros núcleos.

Essas intervenções múltiplas permitiram uma alteração na condução e planejamento da formação continuada dos educadores, e foi possível perceber uma maior abertura por parte dos formadores para discutir a proposta político-pedagógica, bem como para avaliar a coerência das práticas nos diferentes núcleos. Como resultado, 
estruturou-se, por parte da coordenação geral, uma "Comissão de Formação" composta por coordenadores, cujo objetivo é sistematizar os avanços metodológicos da EJA como forma de reconfigurar o processo de formação continuada. A coordenação geral vem promovendo encontros regionais e gerais de formação nos quais os temas abordados emergem das demandas do cotidiano dos professores e coordenadores dos núcleos, abrindo espaço para o compartilhamento de estratégias de mediação, a reformulação dos instrumentos de ensino e aprendizagem, o alinhamento de atitudes frente a questões como avaliação e intervenção nas pesquisas, entre outros.

Os Plantões Institucionais têm sido de fundamental importância para a formação dos coordenadores, que, ao participar deles, têm a possibilidade de, coletivamente, criar novas estratégias para a formação dos professores participantes nos núcleos em que eles atuam. Na avaliação do trabalho realizado no ano de 2014, pode-se constatar que os coordenadores se sentem mais preparados para o desafio de implementar o princípio da transdisciplinaridade, que consiste em ações definidas e planejadas em conjunto, as quais transcendem a divisão disciplinar do conhecimento, junto aos professores dos seus núcleos. Diante disso, avalia-se que a modalidade de intervenção dos Plantões Institucionais foi extremamente valorosa como metodologia de instrumentalização de coordenadores e educadores para o enfrentamento dos desafios da EJA no município.

\section{Considerações finais}

Considera-se que a experiência de estágio de estudantes do curso de Psicologia da UFSC junto à EJA tem qualificado seu aprendizado teórico, prático e reflexivo acerca dos processos de ensino-aprendizagem e da atuação da Psicologia neste campo, contribuindo para a formação de psicólogos escolares e educacionais críticos, além de caracterizar-se como um campo fértil para interlocução com outras áreas da Psicologia, como a organizacional e a social, estabelecendo ainda o diálogo com outras áreas do conhecimento, como Serviço Social, Direito, Pedagogia, Artes, entre outras.

A estratégia utilizada para atuar na gestão da EJA junto à coordenação geral e aos coordenadores dos núcleos mostrou-se exitosa para o aprimoramento do processo 
pedagógico com base na pesquisa, como princípio proposto por essa política. As problematizações suscitadas em relação ao processo de formação continuada e às relações estabelecidas entre coordenadores e professores foram acolhidas pela coordenação, tornando perceptível uma real disposição para alinhar as práticas organizacionais aos princípios filosóficos que norteiam a proposta pedagógica.

Avançamos muito no que se refere ao acolhimento das críticas e dúvidas em relação ao método e à proposta de educação. Falas que eram silenciadas ou ignoradas passaram a ser acolhidas sistematicamente nos espaços de troca que foram sendo criados ou fortalecidos, como os encontros regionais. A Pesquisa como Princípio Educativo passou a ser tema das formações gerais, em que se debatem os princípios e os métodos da proposta entre todos os professores, dos mais experientes aos recém contratados, tornando a formação orgânica e mantendo vivos os princípios transformadores da e pela prática.

O nosso entendimento é o de que a experiência acumulada dos professores deve ser compartilhada, para que as trocas intersubjetivas auxiliem na solução dos problemas por eles próprios enfrentados no cotidiano. O entendimento compartilhado de situações específicas, mediado pelos conhecimentos que pudemos acrescentar, tem sido o grande avanço na perspectiva de uma formação de professores realizada “com" eles e não "para" eles.

Por fim, a possibilidade de estar presente nos diferentes espaços em que os sujeitos que constroem a EJA circulam - formação, planejamento, sala de aula, encontros regionais e gerais, plantões institucionais - ampliou a visibilidade do trabalho desenvolvido pela Psicologia neste contexto de formação de professores, a compreensão mais abrangente dos fenômenos atravessadores e a efetividade das intervenções junto à coordenação geral.

Cabe ressaltar, mais uma vez, que este trabalho só foi possível por ser realizado em parceria, ou seja, com a implicação dos sujeitos participantes. A costumeira abertura da coordenação geral da EJA do município e a confiança depositada nesta parceria são ingredientes fundamentais na formação do vínculo com os profissionais e no 
engajamento dos mesmos no processo de reconstrução do processo de formação continuada.

Compreendemos que ser psicólogo é (re)inventar-se de acordo com o contexto em que se está atuando, porém tendo, como pontos centrais, a validação existencial do outro, a leitura dos fenômenos e a intervenção sobre estes, o cuidado com o ser humano, e, principalmente, a disposição para estar junto. Além disso, compreendemos que a importância do olhar da Psicologia na formação de professores em EJA deve levar em conta a subjetividade daqueles que dela fazem seu campo de trabalho, vida e muitas vezes paixão. Ou seja, um espaço de trabalho e desafios, mas também de perspectivas e frustrações que fazem do elemento humano ligado a este campo uma pedra fundamental que não pode apenas ser citada, mas que deve ser considerada como um dos aspectos determinantes de uma formação de educadores ética, crítica e criativa.

\section{Referências}

ALMEIDA FILHO, Naomar. Transdisciplinaridade e saúde coletiva. Revista Ciência e Saúde Coletiva. v.11, n.1/2, 1997. Disponível em:

<http://ucbweb2.castelobranco.br/webcaf/arquivos/23679/9240/transdisciplinaridade_e_s aude_coletiva.pdf $>$ Acessado em Abr. 2015.

BERGER, Daniel Godinho. Trajetórias territoriais dos jovens da EJA. 2009, oof, Dissertação ( Mestrado em......) - Universidade Federal de Santa Catarina, Mestrado em....., Florianópolis, 2009. Disponível em <http://portal.pmf.sc.gov.br/arquivos/arquivos/pdf/06_12_2011_9.04.10.37220d6a02fadgd1 f94fe3828ezbcd96.pdf> Acessado em Jun.2014.

BRASIL. Lei $n^{\circ}$ 9.394. Lei de diretrizes e bases da educação nacional. Brasília, DF : MEC, 1996. Disponível em: http://portal.mec.gov.br/arquivos/pdf/ldb.pdf Acessado em Jun.2014.

CARVALHO, Diana Carvalho de. As contribuições da psicologia para a formação de professores: algumas questões para debate. In: MARASCHIN, Cleci; FREITAS, L. B. L.; CARVALHO, D. C. de C. (Orgs.). Psicologia \& educação: multiversos sentidos, olhares e experiências. Porto Alegre: Editora da UFRGS. 2003. 
COIMBRA, Cecília Maria Bouças; NASCIMENTO, Maria Lívia do. Sobreimplicação: práticas de esvaziamento político? In: ARANTES, E. M. M.; NASCIMENTO, M. L. e FONSECA, T. G. Práticas Psi inventando a vida. Local: EdUFF, 2007, p. 27-38.

DAVIES, Nicholas. O financiamento da educação estatal no Brasil: desafios para sua publicização. Revista de Educação Pública (UFMT), n.19, p. 229-245, 2010.

FALEIROS, Elisabeth Amélio. Aprendendo a ser psicoterapeuta. Psicologia ciência e profissão. Brasília, v.24, n.1, 2004. Disponível em:

$<$ http://www.scielo.br/scielo.php?script=sci_arttext\&pid=S1414-

$98932004000100003 \&$ lng=pt\&nrm=iso >. Acessado em Mar.2015.

FLORIANÓPLIS.Secretaria Municipal de Educação Estrutura, funcionamento, fundamentação e prática na educação de jovens e adultos - EJA 2008. Florianópolis/SC, 2009.

FREITAS, Maria de Fátima Quintal de. Educação de jovens e adultos, educação popular e processos de conscientização: intersecções na vida cotidiana. Educar, , n. 29, 2007, p. 4762.

FRIEDRICH, Márcia; BENITE, Cláudio R. Machado; BENITE, Anna M. Canavarro. O Programa Nacional de Inclusão de Jovens: Projovem: uma análise entre a proposta oficial e a experiência vivida em Goiânia. Aval. Pol. Públ. Educ., v.20, n.74, 2012, p.185-206,

FURINI, Doris R.; DURAND, Olga C.; SANTOS, Pollyana. Sujeitos da educação de jovens e adultos, espaços e múltiplos saberes. In: LAFFIN, Maria H. (Org.). Educação de jovens e adultos e educação na diversidade. Florianópolis: NUP/UFSC, 2011. p. 158-245.

GESSER, Marivete. Políticas públicas e direitos humanos: desafios à atuação do Psicólogo. Psicol. Cienc. Prof. v.33, n. especial, 2013, p. 66-77.

LAFFIN, Maria. H. L. F. Mediações pedagógicas na educação de jovens e adultos. In: LAFFIN, Maria. H. L. F. Educação de jovens e adultos e educação na diversidade. Florianópolis: NUP/UFSC, 2011. p. 246-279

LAFFIN, Maria. H. L. F.; NAKAYAMA, A. R. O trabalho de professores/as em um espaço de privação de liberdade. Educação e Realidade. v.38, n.1, 2013, p.155-178.

LERNER, Ana Beatriz Coutinho; FONSECA, Paula Fornata; SAYÃO, Yara e MACHADO, Adriana Marcondes. Plantão institucional: uma modalidade de intervenção face ao malestar contemporâneo na educação. Estilos da Clínica, , n.19, 2014, p.199-208. 
MACHADO, Adriana Marcondes. Formas de pensar e agir nos acontecimentos escolares: criando brechas com a psicologia. In: FACCI, M.; MEIRA, M. e TULESKI, S. (Orgs.). A exclusão dos "incluídos": uma crítica da psicologia da educação à patologização e medicalização dos processos educativos. Maringá: Eduem, 2011.

MADUREIRA, Ana Flávia do Amaral. Psicologia escolar na contemporaneidade: construindo "pontes" entre a pesquisa e a intervenção. In: TUNES, Elizabeth. $\mathbf{O}$ fio tenso que une a psicologia à educação. Brasília: UNICEB, 2013. p. 55-74

MARINHO-ARAÚJO, Claisy Maria; ALMEIDA, Sandra Francesca Conte de. Delimitando espaços, estabelecendo conexões - educação e escola. In: Psicologia escolar: construção e consolidação da identidade profissional. $3^{\text {a }}$ ed. Campinas, SP: Editora Alínea,2010.

MARTINEZ, Albertina. O que pode fazer o psicólogo na escola. Em Aberto. Brasília, v.23, n.83, 2010, p. 39-56,

MORENO, Jacob Levy. Fundamentos do psicodrama. São Paulo: Summus,. ,1959/1983. V.20.

NERY, Maria da Penha. Grupos e intervenção em conflitos. São Paulo: Ágora, 2010.

NERY, Maria da Penha. ; COSTA, Liana Fortunato. A pesquisa em psicologia clínica: do indivíduo ao grupo. Estud. Psicol. Campinas, v.25, n.2, 2008. Disponível em:

$<$ http://www.scielo.br/scielo.php?script=sci_arttext\&pid=S0103-

166X2008000200009\&lng=pt\&nrm=iso >. Acessado em Jul. 2014.

PEDRALLI, Rosângela; CERUTTI-RIZZATTI, Mary Elizabeth. Evasão escolar na educação de jovens e adultos: problematizando o fenômeno com enfoque na cultura scrita. Revista Brasileira de Linguística Aplicada. v.13, n.3,2013, p. 771-788.

PINO, Angel. Psicologia concreta de Vigotski: implicações para a Educação. In: Autor.... Psicologia \& educação: revendo contribuições. São Paulo: Educ Fapesp, 2000.

RODRIGUES, G. T.; AGOSTINHO, S. C.; GESSER, M.; OLTRAMARI, L. C. Psicologia e educação de jovens e adultos: um desafio em construção. Psicol. Esc. Educ.,, v.18, n. 1, Jun. 2014, p. 181-184.

SANTOS, Geovânia L. Educação ainda que tardia: a exclusão da escola e a reinserção de adultos das camadas populares em um programa de EJA. Revista Brasileira de Educação. v.24, n.1, 2003, p.07-125.

SOARES, Leôncio. O educador de jovens e adultos e sua formação. Educação em Revista. v.47, 2008, p. 83-100. 
SOARES, Poliana Galvão; MARINHO-ARAÚJO, Claisy Maria. Práticas emergentes em Psicologia Escolar: a mediação no desenvolvimento de competências dos educadores sociais. Psicologia Escolar e Educacional. v.14, n. 1, 2010, p. 45-54.. Disponível em: <http://www.scielo.br/pdf/pee/v14n1/v14n1a05.pdf>. Acessado em Abr.2015.

SZYMANSKI, Heloisa. Entrevista reflexiva: um olhar psicológico sobre a entrevista em pesquisa. In: SZYMANSKI, Heloisa (Org.). A entrevista na pesquisa em educação: a prática reflexiva. $3^{\mathrm{a}}$ ed. Brasília: Liber Livro Editora, 2004, , 2010.

TONETTO, Aline Maria; GOMES, William Barbosa. A prática do psicólogo hospitalar em equipe multidisciplinar. Estudos de Psicologia. Campinas, v.24, n.1, 2007, p.89-98.. Disponível em: <http://www.jornallivre.com.br/16123/a-pratica-do-psicologo-hospitalarem-equipe-multidisciplinar.html>. Acessado em Mar.2015.

UNESCO. Relatório global de aprendizagem e educação de adultos. Brasília: Unesco, 2010.

VIGOTSKI, Lev Semenovitch. A formação social da mente: o desenvolvimento dos processos psicológicos superiores. In: COLE, M., STEINER, V. J., SCRIBNET, S. SOUBERMAN, E. (Orgs). Inserir título da obra. São Paulo: Martins Fontes, 2002. 